\title{
Student research laboratory for optical engineering
}

Nadezhda Tolstoba, Azaliya Saitgalina, Polina Abdula, Daria Butova

Nadezhda D. Tolstoba, Azaliya Saitgalina, Polina Abdula, Daria Butova, "Student research laboratory for optical engineering," Proc. SPIE 9793, Education and Training in Optics and Photonics: ETOP 2015, 97931Y (8 October 2015); doi: 10.1117/12.2223186

Event: Education and Training in Optics and Photonics: ETOP 2015, 2015, Bordeaux, France 


\title{
Student research laboratory for optical engineering
}

\author{
Nadezhda D. Tolstoba, Azaliya Saitgalina, Polina Abdula, Daria Butova
}

\author{
Dept. of Applied and Computer Optics, ITMO University, \\ 49 Kronverkskiy Prospect, Saint Petersburg, Russia, 197101
}

\begin{abstract}
Student research laboratory for optical engineering is comfortable place for student's scientific and educational activity. The main ideas of laboratory, process of creation of laboratory and also activity of laboratory are described in this article.

At ITMO University in 2013-2014 were formed a lot of research laboratories. SNLO is a student research (scientific) laboratory formed by the Department of Applied and computer optics of the University ITMO (Information Technologies of Mechanics and Optics). Activity of laboratory is career guidance of entrants and students in the field of optical engineering. Student research laboratory for optical engineering is a place where student can work in the interesting and entertaining scientific atmosphere.
\end{abstract}

Keywords: student's laboratory, laboratory, optics engineering, applied optics, education, optics.

\section{INTRODUCTION}

Students from the first course study optics at faculty of Optical information systems and technologies, but the main accent is directed on theoretical material. The material is difficult, besides, not each student is started up in scientific laboratories; independent work in laboratory is complicated. In usual laboratory it is unprofitably to use the expensive equipment for the initial stage of studying optics.

Communication turns out quite formal if communication happens between the teacher and the student. So it was always accepted in Russia. Students of our chair after visiting other countries, passing training and passing education with the Double Degree program paid attention to availability of equipment in student scientific laboratories. But the work was organized sometimes formally too.

\section{STUDENT RESEARCH LABORATORY FOR OPTICAL ENGINEERING}

At the beginning of 2014 on chair of Optical information systems and technologies the Student scientific laboratory for optical engineering was open. Initiative students and teachers wanted to work not on a template which impose current trends of a development of education, but to create own line of training. The project about a new form of involvement for students in scientific and educational activity was approved by our staff and the head of the department Applied and computer optics [1]. By joint discussion, the idea of creation of comfortable place for student scientific and educational activity arose. We began involvement of students to the scientific sphere with implementation of small projects which and are kept to this day.

After receiving audience for our laboratory the main and initial objective was the organization the place of laboratory. The tasks providing laboratory with the equipment they also were successfully solved.

Education and Training in Optics and Photonics: ETOP 2015, edited by Eric Cormier, Laurent Sarger Proc. of SPIE Vol. 9793, 97931Y · (c) 2015 SPIE, IEEE, OSA, ICO · doi: 10.1117/12.2223186 


\section{WORKSHOPS}

Cooperation with other student laboratories, such as Open Laboratory of Ideas, Methods and Practices OLIMP [2-3] and FABLAB of ITMO was an important stage in development of our laboratory. We have joint projects which are successfully realized. From OLIMP colleagues we got an experience with collective. Thanks for support of our colleagues we reconsidered our views of carrying out actions for training of students.

For each project was organized the team and the student of our laboratory becomes project manager. Such teams are called "workshops" [3]. The workshop opens for the term of work on the project and this term at all one. All workshops are working till the festival and making projects to show on it. The festival is the main action and logical completion of activity workshop.

\subsection{Workshop of three-dimensional optical illusions}

The main objective of this workshop is to teach students to create optical illusions with use of various graphic programs and studying methods of creation three-dimensional optical illusions. It is a new art form works at a joint of equipment and art. To the end of the project the best work which will be realized for registration for place of chair will be chosen. Following the results of work of a workshop the conclusion was drawn that the best illusion for our place is illusion on the basis of the grid distorting space.

\subsection{The optical projects workshop}

Work of this workshop is directed on involvement of entrants to occupations by science and optics.

\section{Project: Optical equipment kit}

This project helps laboratory to get the equipment for the experiments which are taking place in all workshops. This project would be impossible without financing, or without interaction with other laboratories. Participation in the OLIMP project mentioned above had positive impact. For example, development of designs of fastenings, prototyping, receiving ready samples and checking of their working capacity in practice.

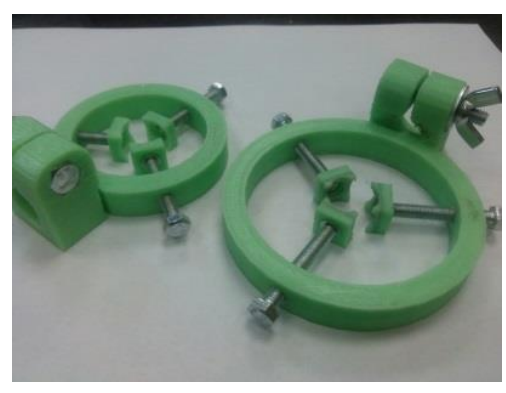

Fig. 1. Optical equipment kit

\section{Project: Blaster}

Students create the device working as the game blaster in infrared area. This task is multidimensional: independent assembly, calculation of characteristics, the analysis and obtaining the improved characteristics of operation of the device by using optical elements available in laboratory. At the end the device can be used as the model for games.

\section{Project: interactive optical stand}

It became available for SNLO to have a stand, which we decided to use as a teaching resource for enrollees and students. 

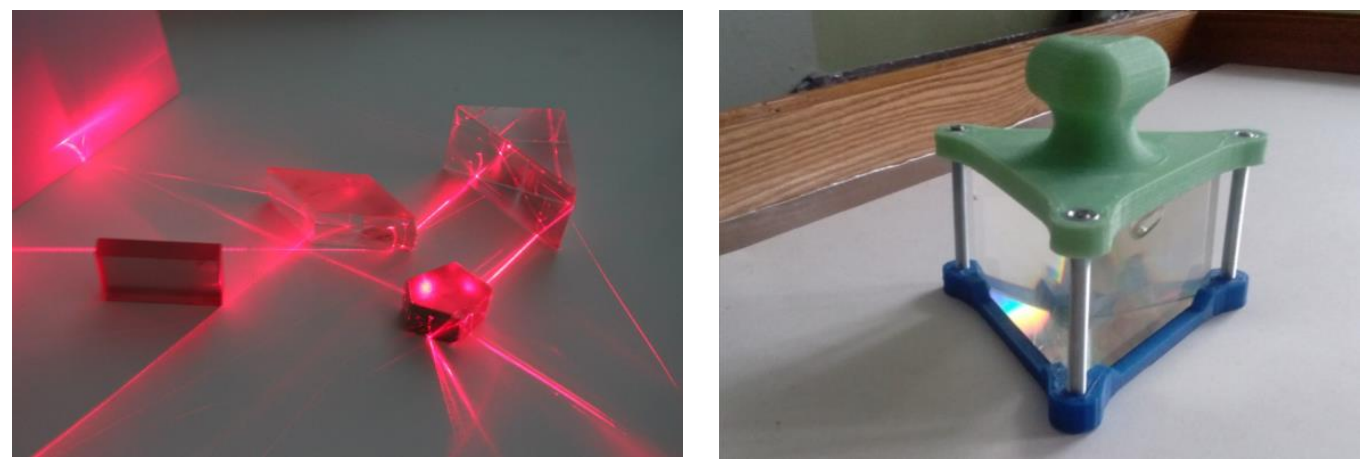

Fig. 2. Interactive optical stand

In the end of common work about production of units, the stand was worked out. You could easily move fixed prisms on a magnetic leaf and place them in the best way to explore and see the actions of prisms and prismatic systems. This stand is required for our students.

The participants of workshop work in computer-aided engineering (CAE) programs, learning the basics of professional work and receiving outrunning knowledge of their educational programs.

\subsection{Engineering of optical sight workshop}

This project is initiative. The goal of this workshop is to design and collect night TV optical sight.

The feature is that it works in passive and active mode. Its searching system has viewing angle of 180 degrees in passive mode and 5 degrees in active mode. The reticle projects with a monitor. It represents white stripes on the black background itself. It helps to avoid illumination of the screen. This sight will not have analogues. Students carry out calculations and develop housing, electronic circuit and optics of this device. The work moves rapidly and professionally.

\section{4. Co-working area of optical engineering}

The goal of this workshop is to organize an area, in which students of different levels will cooperate, find common tasks and solve them. This area already has a few directions of work - studying, projective and scientific.

\section{Educational direction}

We want to stress the club of playing English, where students relax and improve their language skills and the overall outlook at the same time. Different workshops, lections on topical areas and interests take place there. Next year lessons for junior students will be organized on the base of the lab.

\section{Project: Optical maze game development}

SNLO received an offer to participate in the trip of scientific community representatives from our university to China. That moment we mobilized our efforts to show interesting project to our Chinese friends.

At that moment appeared the idea of making the maze game, on the basis of which show and tell about optics in new format.

There were developed two mazes: Challenge Quest and "ITMO-China". Challenge Quest was developed by the students of the department and made in the FabLab ITMO. The main feature of the maze is its uniqueness. There are lots of holes on the base of plateau, where in different order can be put partitions that form obstacles for the beam path. 
The maze "ITMO-China" (Fig 3.) is made in the form of the logotype ITMO. As it is known, the red point means SaintPetersburg, where ITMO University is situated. It was Challenge for Chinese students within the framework ITMO Day in leading Chinese universities. The main feature of this maze is that there is provided also lighting part.

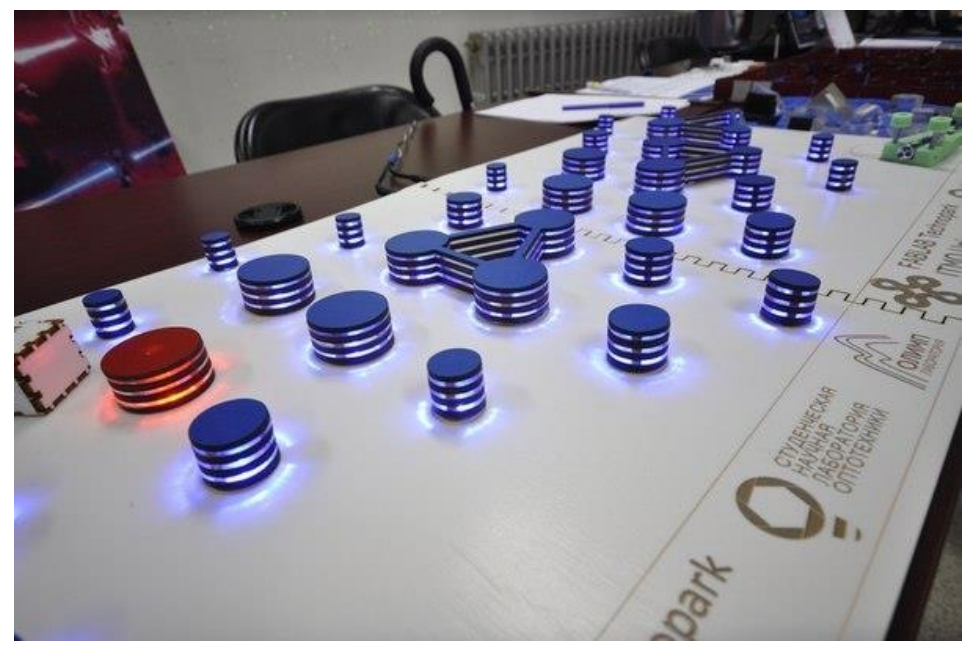

Fig. 3 The LED maze "ITMO-China"

\section{Project: Developing tasks to demonstrate optical events}

Also senior students work out different optical experiments for junior students. These experiments demonstrate the easiest things in geometrical optics, for example total internal reflection and the influence of temperature on the beam refraction in water. Thanks to developed optical equipment kit everyone can participate in the formulation of new experiments, observe the work of colleagues and learn independently collect optical schemes: for example, telescopic Kepler and Galileo systems, scheme for observing interference pattern and others interesting versions of schemes. These stands and equipment may be successfully used for subjects, courses and study curriculum implemented by the department.
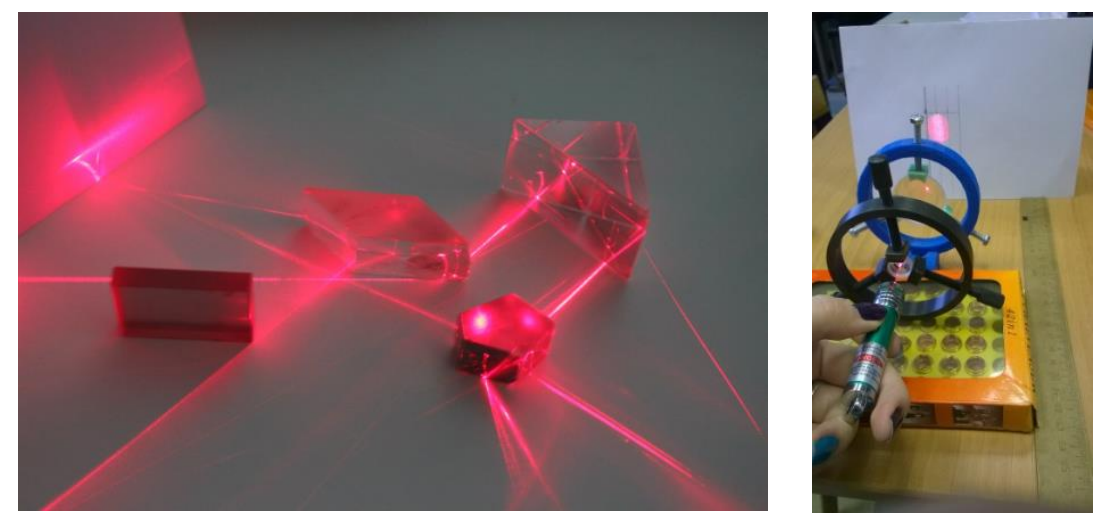

Fig.4 Tasks for demonstration of optical phenomena

\section{Work with schoolkids}

Our laboratory is involved in the work with schoolkids. We talk to them about optics, its elements and effects that can be got through them. This is an important and difficult task. Not all students are familiar with the optical terminology and our students explain material to them more easily, interesting and accessible. Especially for this, our laboratory has prepared new projects and tasks with optical elements. That gives new teaching experience to our students. 


\section{Festival of ideas and projects}

In May 2015, our laboratory has been involved in the festival of ideas and projects, organized by OLIMP. This is a very important and useful event, where we shared our developments and ideas with interested people, talked to them on the themes of projects.

\section{CONTESTS AND EVENTS}

We interact and interchange with the laboratories for many directions. The results in the form of finished projects are only a small part of what we get in the end. FabLab ITMO and OLYMP actively assist in the implementation of our projects, the creation of models.

As our laboratory is involved in social projects "People need you!" In this project, we try to attract children to science and give them the most valuable thing we have: knowledge! And also we try to show how amazing/interesting optics can be!

As part of the laboratory we have master classes and lectures. Together with the optical chapter of the University ITMO students we conduct master classes in technical drawing, introductory lectures on large optical communities such as SPIE, OSA, IEEE.

\section{RESULTS}

We developed and implemented a mechanism of action blaster: working electronic circuit.

Now it is necessary to calculate the working beam diameter and to develop a mount on a professional level. Prototype is only one; the next will be implemented in the rifle.

We upgraded the idea of the stand. It became dynamic. Now this interactive stand performs prisms in accurate, reliable and ergonomic mounts. As light sources we use a simple laser pointer because of affordability, and also we developed mounts: with them we can adjust the direction of the beam axis.

\section{CONCLUSIONS}

Students got enormous experience in laboratory even at a stage of its formation: it is experience of collective work, time management of the tasks, experience of organization of events, teaching practice.

Besides, the laboratory is not located in the main case of ITMO University. With the advent of laboratory increased possibility not only in laboratory, but also visit of occupations.

Creation of laboratory motivates students on further development of laboratory, the desire to advance scientific works and receiving grants for development of laboratory is connected with it.

\section{REFERENCES}

\section{[1.] http://aco.ifmo.ru/about_eng.html}

[2.] Bodrov K.Yu., Ivashchenko M. I. Development of the concept of open student's laboratories on the example OLIMP, the Collection of theses of reports of the congress of young scientists. Electronic edition. - SPb: ITMO university, 2015. [3.] Bodrov K.Yu., Ivashchenko M. I. Self-education and initiative of students as investments into the future of science, economy and industry. Collection of theses of reports of the congress of young scientists. Electronic edition. - SPb: ITMO University, 2015. 